\title{
La biotecnología de Bacillus thuringiensis en la agricultura
}

Diana Daniela Portela-Dussán ${ }^{1}$, Alejandro Chaparro-Giraldo ${ }^{1}$, Silvio Alejandro López-Pazos ${ }^{1,2}$

1. Grupo de Ingeniería Genética de Plantas, Departamento de Biología, Universidad Nacional de Colombia, A.A 14-490, Bogotá D.C., Colombia.

2. Facultad de Ciencias de la Salud, Universidad Colegio Mayor de Cundinamarca, Bogotá D.C., Colombia

Correspondencia: salopez@unicolmayor.edu.co

Recibido: 04/03/2013 Aceptado: 23/05/2013

\section{Resumen}

Bacillus thuringiensis es un bacilo Gram positivo que durante su fase de esporulación produce una inclusión parasporal, conformada por proteínas Cry con actividad biológica contra insectos-plaga. Gracias a estas proteínas Bacillus thuringiensis presenta toxicidad contra larvas de insectos-plaga de los órdenes Lepidóptera, Coleóptera y Díptera, entre otros. Además es amigable con el medioambiente, razones por la cuales se ha hecho común el uso y desarrollo de productos comerciales y plantas transgénicas a base de toxinas Cry en el sector agrícola. En esta revisión se describirá los aspectos más importantes de Bt y su aplicación como herramienta biotecnológica para el sector agrícola, con una consideración sobre bioensayos usando esta bacteria.

Palabras clave: Bacillus thuringiensis, biopesticida, insecto-plaga, planta transgénica, proteína Cry, ensayo biológico.

\section{Bacillus thuringiensis biotechnology in agriculture}

\begin{abstract}
Bacillus thuringiensis $(B t)$ is a Gram-positive rod-shape bacterium that during its sporulation phase produces a parasporal inclusion formed by Cry proteins having biological activity against pest insects. Because of these proteins, $B t$ shows toxicity toward pest insect larvae of Lepidoptera, Coleoptera and Diptera orders among others, besides of friendly with the environment, and for this reason $B t$ has a very common use for commercial products and transgenic plants with Cry protein basis in agriculture. In this review is described the most important $B t$ factors and their application as biotechnological tool in agrobusiness, considering Bt bioassays.
\end{abstract}

Key words: Bacillus thuringiensis, Cry protein, pest insect, biopesticide, transgenic crop. 


\section{Introducción}

Los cultivos comerciales constituyen una fuente importante para la economía del mundo, ya que parte de la base alimentaria de la población descansa en la producción agrícola, situación que requiere la atención por parte de los gobiernos. Uno de los principales factores que se debe controlar para evitar la volatilidad de la producción son los insectos-plaga, pues se estima que la producción agrícola mundial se ve afectada aproximadamente en un $18 \%$ por esta causa, situación por la cual se considera que anualmente deja pérdidas de miles de millones de dólares (1).

Una herramienta de la biotecnología para afrontar esta problemática es la aplicación de las propiedades de la bacteria entomopatógena Bacillus thuringiensis $(B t)$, un bacilo Gram positivo, aerobio facultativo, esporulado, cuyo tamaño oscila entre 1 a 1.2 micrómetros de ancho y de 3 a 5 micrómetros de largo $(2,3)$, nativo del suelo y catalogado como cosmopolita (4-6) la cual se ha aislado de ecosistemas como bosques tropicales y templados, zonas desérticas, sabanas, archipiélagos, frutales, suelos agrícolas, arena y cuevas en los cinco continentes (6-9). Pertenece al reino Eubacteria, a la familia Bacillaceae y al género Bacillus junto con $B$. cereus y $B$. anthracis, de los cuales se diferencia por la formación de una inclusión parasporal refringente al microscopio de contraste de fases (3).

La inclusión parasporal, puede ocupar hasta el 30\% de la célula y se produce en la fase estacionaria de crecimiento de la bacteria. Esta inclusión está conformada por diversas estructuras proteicas, denominadas Cry y Cyt (3). Las proteínas Cry son el principal factor de virulencia de $\mathrm{Bt}$, las cuales poseen pesos que oscilan entre -60 y $140 \mathrm{kDa}$, y que al estar en presencia de un ambiente reductor modifican su estructura volviéndose altamente tóxicas contra insectos de los órdenes Lepidóptera, Díptera, Coleóptera Himenóptera, Homóptera, Ortóptera y Malófaga $(3,11)$. Las proteínas Cry han sido utilizadas ampliamente como biopesticidas o en el desarrollo de cultivos transgénicos. En esta revisión se describen los aspectos más relevantes en la aplicación biotecnológica de $B t$ en la protección de especies vegetales comerciales.

\section{Proteínas Cry}

La forma estructural de las toxinas Cry está constituida por tres dominios determinantes para su actividad biológica contra insectos.

El dominio I consiste en un paquete de siete $\alpha$-hélices antiparalelas, donde la hélice 5 está rodeada por las demás; el dominio II consta de tres láminas antiparalelas $\beta$ distribuidas en una típica topología de "llave griega", acomodada en lo que se ha llamado un $\beta$-prisma; el dominio III consiste de 2 láminas $\beta$ antiparalelas formando un $\beta$ sándwich (12-14). El dominio I es el responsable de la formación del poro, el cual se cree que adquiere su forma final de poro por acción de las hélices $\alpha 5 \mathrm{y}$ $\alpha 6$ que se juntan manera de bucle en el extremo de la estructura insertándose en la superficie de la membrana lipídica de las células intestinales del insecto susceptible.

Dado que la conformación de las láminas $\beta$, del dominio II, tienen parecido con regiones de unión antígeno-anticuerpo en otras proteínas, además de su relación con las lectinas, se considera que esta zona reconoce el receptor de superficie en la membrana apical del intestino del organismo que es sensible a estas toxinas. Finalmente, se tiene evidencia de que la estructura de $\beta$-sándwich del dominio III mantiene la estructura de la toxina, principalmente hacia el ataque de proteasas, reconoce al receptor (conjuntamente con el dominio II) y tiene funcionalidad en la formación del poro lítico $(2,15)$. En consideración de la estructura de tres dominios funcionales de la proteína Cry, el dominio II es una zona altamente variable, y se considera que es el principal determinante de la especificidad ya que está encargado de reconocer al receptor del insecto (Figura 1). 
Por otro lado, se ha descubierto que las toxinas Cry presentan cinco bloques conservados. El bloque 1 está conformado por cinco hélices del dominio I, una zona altamente conservada, por lo que se cree que está implicado en la formación del poro. El bloque 2 incluye siete hélices de dominio I y la primera lámina $\beta$ del dominio II, es la región de contacto de estos dominios, lo cual puede ser importante si el dominio I cambia su orientación relativa para la interacción con el receptor, y para mantener la forma globular de la proteína durante la solubilización y activación $(2,15,16)$. Los bloques 3,4 y 5 se encuentran dentro del dominio III $(2,15)$. El bloque 3 contiene la última lámina $\beta$ del dominio II, una estructura involucrada en las interacciones entre los dominios II y III $(2,15)$. El bloque 4 contiene 2 argininas centrales envueltas en los puentes salinos, involucrados en la agregación oligomérica . La razón biológica del bloque 5 no es clara (15).

\section{Mecanismo de acción de las toxinas Cry}

El insecto cuando consume la proteína Cry presenta cese de la ingesta, parálisis del intestino, vómito, diarrea, descompensación osmótica, parálisis total y la muerte $(10,17,18)$. Para que se lleve a cabo la muerte del insecto, la protoxina debe estar presente en un ambiente reductor que desestabilice sus puentes disulfuros y pueda ser activada. Dependiendo de la naturaleza de la proteína Cry se realizará la solubilización y activación de la misma, pues se ha demostrado que las proteínas Cry1 presentan mayor cantidad de aminoácidos básicos por lo cual los cristales se solubilizan a un $\mathrm{pH}$ alcalino presente en el intestino medio del insecto; si es una proteína Cry3 existen cuatro puentes salinos intercatenarios que estabilizan el cristal por lo que se puede solubilizar en $\mathrm{pH}$ ácidos ( $\mathrm{pH} 5$ - 6) , aunque pueden estar activadas naturalmente $(10,18)$.

Sin embargo para que sean activadas no es suficiente con la solubilizacion, se requiere de la acción de la proteasas presentes en el intestino medio del insecto, escindiendo una sección de aminoácidos en la región $\mathrm{N}$ - terminal y en el extremo $\mathrm{C}$ - terminal dependiendo de la naturaleza de la proteína Cry, dejando una toxina activa de un peso molecular oscilante de 49 a 70kDa. $(10,19,20)$.

Se ha encontrado que las enzimas digestivas que predominan en los lepidópteros y dípteros son las tripsina, quimiotripsina, serino - proteasas y termolisinas; mientras que en los coleópteros predominan la quimiotripsina, cisteíno y aspartato proteasas $(10,18)$. Una vez se activa la toxina, ésta debe reconocer receptores específicos sobre vesículas de membrana de la microvellosidad apical de las células columnares del intestino medio (VMMA) (19). Esta unión se realiza en dos fases, una reversible, en la que se da la interacción entre la toxina y su sitio de unión, del receptor en la que actúan los dominios II y III y otra irreversible en la que la proteína se une a la proteína receptora del insecto susceptible, insertándose en la membrana, lo cual requiere de la actuación del dominio I (21). Entre los receptores encontramos caderinas, aminopeptidasa $\mathrm{N}$ (APN), fosfatasa alcalina y proteínas de $210 \mathrm{kDa}(10,21)$.

Una vez se ha dado la inserción dentro de la membrana apical, la toxina induce la formación de canales de iones o poros con un diámetro de 1 a 2 nanometros en la membrana celular en forma de oligómeros que rompen el potencial de membrana $(2,21)$, esto finalmente hace que se aumente la permeabilidad de la membrana celular, permitiendo la entrada de agua, aniones, cationes, afectando el $\mathrm{pH}$ al alcalinizar el citoplasma y permitiendo la entrada de moléculas de mayor peso molecular que finalmente destruirán el epitelio intestinal (22). Una vez se destruye el epitelio las esporas de $B t$ se introducen en la hemolinfa donde se difunden generando una septicemia y muerte de la larva $(10,18,21)$. 
A 3AaldII

8Aa1DII

3Aa1DII

8Aa1DII

3Aa1DII

8Aa1DII

3Aa1DII

8Aa1DII
TLTVLDLIALPPLYDVRLYPKEVKTELTRDVLTDP IVGVWMLRGYGTTFSNIEN-YIRKP 59

TTRELTRDVYTDP IRFNIVTSTGECWPWSTHSGILFYEVEWNV IRPP 47

$:^{\star}, . \quad:::::^{\star} \ldots$.

* * : : :*

HLPD YHRIQPHTRFQPGYYGNDSFN-YWSGNYVSTRPSIGSNDIITSPFYGNKSSEPVQ 118 HLFD ILSSVE INTSRGGITUWNDAYINYWSGHTUKYRRTADS-TVTYT\&NYGRITSE-KN 105

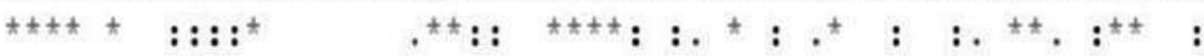

MLEFNGEKVYRAVANTW-IRVWPSAYYSVTKVEESQYNDQTDEASTQTYDSKRNVG--- 174 SFALEDRD IFEINSTVAMLNYYQKAY-GVPGSWEHMVRGTSSTTRYLYSKHTAIQGC 164

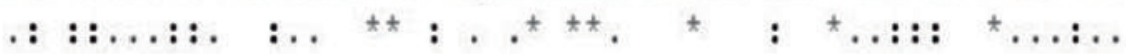

AVSWDSIDQLPPETTDEPLEKGYSHQLNYVMCFLMQGSR----GTIPVLTWTHKSVD 227 TQVYESSDEIPLDRT-VPVAESYSHRLSHITSHSESKHGSAYYGSPPVYWTHTSAD 220

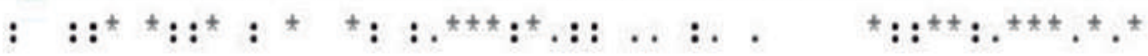

B

\begin{tabular}{|c|c|c|}
\hline Residuo & Color & Propiedad \\
\hline AVFPMILW & Rojo & Pequeña (pequeña + hidrofóbica) \\
\hline DE & Azul & Acidico \\
\hline RK & Magenta & H-Básico \\
\hline STYHCNGQ & Verde & Hidroxil+sulfidril+amino+G \\
\hline Otros & Gris & inusual amino/aminoácidosetc \\
\hline
\end{tabular}

Figura 1. Comparación entre los dominios II de las toxinas Cry3Aa y Cry8Aa. A. Se puede observar la alta variabilidad, el asterisco indica identidad, los dos puntos corresponde a sustitución conservativa y el punto enseña sustitución semiconservativa. El alineamiento se realizó con el programa Clustal Omega (http://www.ebi.ac.uk/Tools/msa/clustalo/). B. La tabla de la parte inferior relaciona la escala de colores vs tipo de aminoácido según el programa Clustal Omega.

Formulaciones que contienen a $B t$ y sus toxinas Cry

Debido a su capacidad de combatir insectos plagas sin afectar el medio ambiente, y no generar reacciones adversas en el ser humano u otros seres vivos, el uso de productos a base de $B t$, ha aumentado constituyendo del 1 al 2\% del mercado global de insecticidas, dejando ganancias de
8 billones de dólares por año. De igual forma se considera que el $80 \%$ de los productos biológicos utilizados en la agricultura son preparados con componentes de este microorganismo (20, 23). Para el desarrollo de productos a base de $B t$ se requiere emplear cepas debidamente caracterizadas y que no sean productoras de $\beta$-exotoxina $(20,24$, 25) y su producción se realiza principalmente con 
el método de fermentación sumergida a una temperatura entre $27-35^{\circ} \mathrm{C}$ y un $\mathrm{pH}$ de 6.8 a 7.2 , bajo una regulación de nutrientes, cinética y transferencia de oxigeno adecuada para una buena recuperación de biomasa y proteína insecticida para su posterior formulación y envase $(25,26)$.

Los bioinsecticidas a base de $B t$ se clasifican en productos de primera generación, los cuales están constituidos por esporas y cristales, presentan varios inconvenientes pues presentan un rango estrecho de actividad cuando se presenta más de un insecto plaga, poca persistencia en campo debido a la radiación solar, y no alcanzan insectos que atacan raíces o partes internas del vegetal. Sin embargo, estos problemas se han logrado solucionar con el empleo de productos de segunda generación, que contienen como ingrediente activo esporas y toxinas de cepas con introducción de genes de otras cepas la cual es de gran utilidad al mejorar la acción frente al insecto generando un sinergismo, además de disminuir las posibilidades de resistencia (25).

Los biopesticidas $B t$ de tercera generación, que contienen como ingrediente activo bacterias recombinantes, especialmente Pseudomonas fluorescens o Clavibacter xyli subsp. cynodontis, son capaces de llegar hasta tejidos vegetales y crecer en la rizosfera. La cuarta generación de estos bioinsecticidas la constituyen quimeras de proteínas (25). La compañía Abbott tiene, entre otros, los productos Dipel a base de la serovariedad kurstaki (genes cry1Aa, cry1Ab1, cry1Ac1, cry2Aa1, cry2Ab1) y Xentari (Bt aizawai con genes crylAa1, crylAb1, cry1Ba1, cry1Ca1, cry1Da1) que poseen letalidad hacia insectos lepidópteros. Ecogen Inc. Ha promocionado los biopesticidas Lepinox (a base de Bt kurstaki) y Crymax (cepa Bt ED7826 con genes cry1Ac, cry2A y cry1C) de letalidad hacia lepidópteros. Biochem desarrollo una formula a base de $\mathrm{Bt}$ israelensis para el control de dípteros (toxinas Cry4Aa1, Cry4Ba1, Cry10Aa1, Cry11Aa1). Mycogen desarrollo M-trak, producto por el cual fue demandada por la empresa Novo Nordisk por uso indebido de la cepa.
El estudio continuo de la actividad tóxica de $B t$ ha permitido encontrar nuevas cepas que presentan actividad contra insectos sobre los cuales anteriormente no se había encontrado algún tipo de acción tóxica con proteínas Cry debido a las condiciones del $\mathrm{pH}$ del intestino medio que no eran las apropiadas para su activación (por ejemplo en el orden Coleóptera se ha observado condiciones de $\mathrm{pH}$ intestinal ácido), siendo resistentes a la acción de $B t$, lo cual permite pensar en ampliar la utilidad de esta bacteria y el desarrollo de novedosos biopesticidas (27).

\section{Plantas con genes cry}

La compañía Plant Genetic Systems de Bélgica desarrolló en 1985 la primera planta transgénica de tabaco portadora de genes cry. La primera plantación con un cultivo transgénico en los Estados Unidos se llevó a cabo en el año de 1994, cuando la agencia para la protección ambiental (EPA) aprobó el cultivo de patata Bt, y en 1996 se comenzó la producción a gran escala de este tipo de cultivos. El primer cultivo con genes cry que se comercializó fue el maíz, y posteriormente fueron liberados muchas variedades resistentes a insectos como patata- $B t$, soya- $B t$ y algodón- $B t$, entre otros. Actualmente las plantas transgénicas a base de $B t$ son comercializadas por el sector privado en más de 32 millones de hectáreas alrededor del mundo, más de la mitad son de Estados Unidos, $30 \%$ de Europa y Rusia y el 18\% en compañías Japonesas; el $57 \%$ de las patentes pertenecen a compañías como Monsanto, Micogen, Novartis, AgrEvo, o Syngenta (27-30). Entre las plantas transgenicas desarrolladas están arandano (gen crylAa), algodón y papa (gen crylAc), alfalfa y tabaco (gen crylCa) para resistencia a lepidópteros. También se ha transformado genéticamente berenjena, papa y tabaco con el gen cry3A para resistencia a coleópteros entre otros (27).

La ingeniería genética ha logrado desplazar el uso de insecticidas químicos con el empleo de cultivos transgénicos que permiten resistir a insectos plaga 
dejando ganancias promedio de hasta 60 millones de dólares para algodón anualmente, y entre 19 a 190 millones para maíz (27-29). Para lograr producir plantas transgénicas se han empleado métodos como transferencia de ADN por medio de la bacteria Agrobacterium tumefaciens, la cual posee un plásmido denominado Ti con la capacidad de transferir ADN al genoma de la planta; otros métodos muy eficaces son la transferencia del plásmido portador de genes cry por bombardeo (pistola de genes) o mediante electroporación de protoplastos, suministrando la aplicación de un voltaje causando orificios en los protoplastos donde se insertará la solución de ADN. Estas plantas presentan la característica de producir aproximadamente $1 \mathrm{ng} / \mathrm{mg}$ de proteína Cry soluble $(27,29,31)$.

La transformación de las plantas, mediante la incorporación de genes codificadores de proteínas Cry, trae muchos beneficios: le confiere protección a los tejidos internos, se mantiene una producción constante de proteína por lo cual no requiere de un cuidado rutinario ni mayor gasto económico o de tiempo por parte del agricultor, y no genera un impacto ambiental perjudicial (15). Gracias a estos beneficios que ofrece la tecnología de $B t$ su producción se ha aumentado, desde 1996 hasta el 2009 se han cultivado cerca de 1 billón de hectáreas de tierra y a medida que se avanza en el desarrollo de nuevos productos su comercialización se incrementa, en el año 2009 se llegaron a cultivar hasta 134 millones de hectáreas de tierras en más de 25 países como Australia, México, Estados Unidos, Argentina, China, Sudáfrica e India, entre otros (29).

Esta tecnología ha reducido el uso de pesticidas químicos en 21,000 toneladas (20). Sin embargo en los últimos ańos se ha detectado resistencia por parte de los insectos a este tipo de cultivos, principalmente por el uso de genes $B t$ no específicos, presencia de enzimas proteolíticas en la planta, inhibidores de tripsina, el posible flujo de genes entre plantas transgénicas y silvestres y modificación de receptores en los insectos $(2,29)$.
Para disminuir las posibilidades de generación de resistencia se deben emplear estrategias como de alta/dosis, en donde se garantice la expresión de toxinas que cause un elevado porcentaje de mortalidad en el insecto susceptible, el uso de cultivos normales dentro de los transgénicos para evitar fenómenos de presión selectiva en el insecto a combatir y de esta forma mantener alelos susceptibles dentro de la población, empleando de modelo de refugio activo que se basa en una resistencia cruzada negativa (NCR) en donde un alelo confiere resistencia a una toxina e hipersensibilidad a otra (2).

Otra estrategia consiste en emplear cultivos que expresen más de una toxina con diferente mecanismo de acción y baja homología (por ejemplo no se aconseja el uso de toxinas Cryl en un mismo cultivo), por otro lado, para evitar el flujo de genes a través del polen, se debe evitar usar plantas silvestres, aislar los cultivos, cosechar antes de la floración y el desarrollo de plantas estériles o hermafroditas (2, 27, 29, 31).

\section{Ensayos biológicos con $B t$}

El bioensayo implica la medición del efecto que ejerce un determinado estimulo sobre una población de organismos. Para Bt se mide la potencia del agente activo sobre un estado específico del organismo potencialmente susceptible para lo cuál se aplica una metodología que permite evaluar la actividad tóxica de una cepa, producto activo $\mathrm{u}$ organismo recombinante sin que los resultados se vean afectados por las variaciones propias de los sistemas biológicos (32). No se ha aprobado una estandarización internacional debido a factores variables como la cepa del insecto por lo que cada laboratorio estandariza sus propias metodologías, aunque se han recomendado varios protocolos ya que se descubren nuevas proteínas susceptibles de ser manipuladas para escalamiento de nuevas formulaciones y en la ingeniería del DNA recombinante, procesos que involucran diversos ensayos analíticos (33). 
En cuanto al sustrato alimenticio (dieta) es la herramienta básica que provee un rápido, estandarizado y simple procedimiento que permite estimar la actividad de una cepa microbiana (33). Las dietas pueden ser naturales si implica la utilización de los mismos materiales que el insecto consume en campo; artificiales si los componentes naturales son suplementados con otro tipo de nutrientes que se suponen suplen las necesidades de la plaga o son reemplazados totalmente por materiales diferentes a los naturales; artificiales-merídicas si incluyen a la vez elementos de composición conocida (acido ascórbico, vitaminas, colesterol, etc.) y desconocida (harinas, levaduras, aceites, etc.); y oligídicas si tienen elementos de composición desconocida o materiales crudos. Para adicionar el producto microbiano (esporas, cristales, protoxinas, toxinas activadas u otros) en la dieta del insecto se puede mezclar con el agua de preparación de la dieta, o contaminar superficialmente (el bioproducto se esparce y se deja secar), aplicar microgoteo de la muestra a evaluar a manera de atrayente (generalmente sacarosa), la contaminación del alimento natural (hojas, tubérculos o tallos) con la suspensión de la muestra por aspersión, barnizado o inmersión; con dípteros se utiliza mezclar el ingrediente activo con el agua donde se colocaran las larvas, en insectos de instares avanzados se puede inyectar directamente el producto en el tracto digestivo por vía oral. El agente activo bacteriano debe ser cuantificarse. El bioensayo se realiza con pruebas que consisten en amplios rangos de concentración de producto activo y un control negativo que debe contemplarse agua o soluciones buffer (si el bioproducto lo contiene), y un control positivo (en general una cepa o toxina de la cual ya se reconozca su efecto). En ocasiones se puede usar un control absoluto que puede ser una sustancia letal para el insecto, aunque no este relacionada con el bioproducto a evaluar (32).

Los ensayos biológicos se realizan comúnmente sobre larvas de primer o segundo instar ya que son los estados más susceptibles del insecto, dan una respuesta más exacta del nivel de actividad de la cepa bacteriana, generalmente son los instares a controlar en campo, esta disponible en un número más grande que otros instares, el periodo de bioensayo es generalmente corto y la precisión es más alta ya que la mortalidad es uniforme y los intervalos de confidencia son más pequeños (33). Para evaluar efectos a largo plazo y daños intestinales se puede utilizar instares avanzados. Es conveniente monitorear el peso, tamańo y describir el instar larval, se deben utilizar neonatos de 0 a 12 horas de eclosionadas y con privación de alimento, la mortalidad se evalúa entre 48 a 96 horas. Los diseńos experimentales más empleados son el completamente aleatorizado, cuando la variabilidad natural no tiene ninguna tendencia clara, o el de bloques completamente aleatorizados cuando existe una variable con una tendencia clara. Se considera que 30 es el número mínimo de larvas a emplear por concentración con no menos de 3 repeticiones. Los ensayos biológicos deben repetirse cuatro veces en días diferentes para corregir variaciones dadas por calidad del insecto, condiciones locales o procedimientos experimentales. La respuesta más fácil de evaluar en un bioensayo es el porcentaje de mortalidad. La expresión más empleada de la actividad tóxica es la concentración letal 50 (CL50), parámetro que indica la concentración a la cual se origina la muerte del $50 \%$ de la población de insectos evaluados, aunque en ocasiones se utiliza el tiempo letal 50 (tiempo en que muere la mitad de la muestra analizada) y la dosis letal 50 (donde se tiene que asegurar que el insecto recibe exactamente la concentración a evaluar, se hace generalmente mediante inyección) $(32,33)$.

La selección del insecto problema depende del impacto que tenga ya sea económicamente o en salud. Generalmente se tiene en cuenta las actividades biológicas reportadas para la bacteria, aunque esto no siempre es posible. Los autores tenemos experiencia en insectos para los que no existían reportes de actividad hacia $B t$, pero que su importancia como plagas en Colombia era evidente (Figura 2). Además hay que tener en cuenta que la susceptibilidad de una plaga a las toxinas 
Cry puede deberse a varios factores como el $\mathrm{pH}$ intestinal, el procesamiento por proteasas, o la presencia de receptores especiales (distintos a los mencionados) (Figura 3). Los insectos se pueden obtener directamente de campo o de crías en laboratorio, pero nosotros hemos preferido iniciar las crías de laboratorio con individuos atrapados en campo ya que se evita fenómenos asociados a variabilidad genética que podrían redundar en diversas respuestas a los bioensayos, sobre todo si ya se tienen muchas generaciones del insecto en laboratorio. Para nuestro laboratorio preferimos renovar las crías constantemente (máximo cuando lleguen a 10 generaciones).
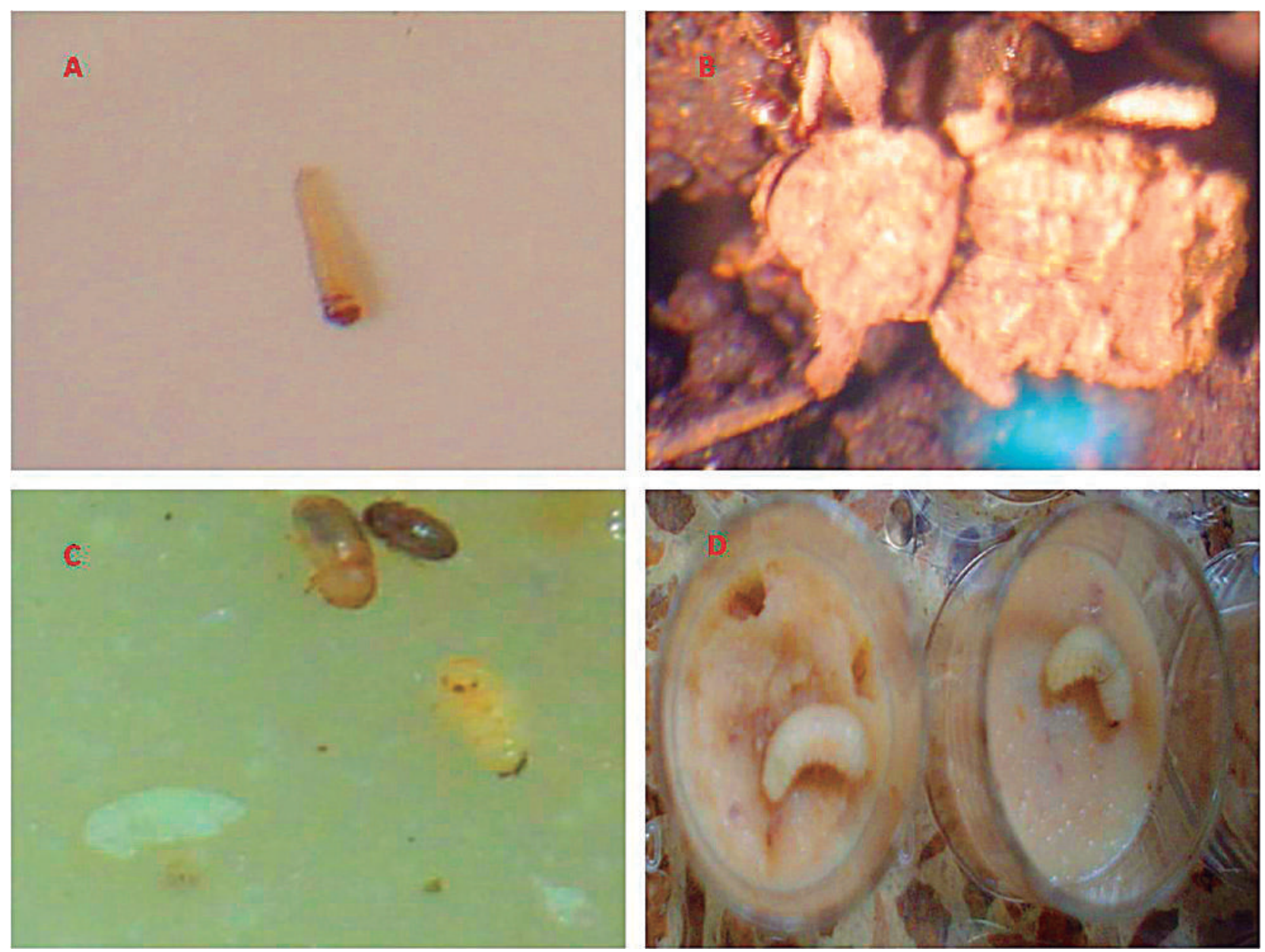

Figura 2. Insectos plaga de importancia en Colombia. A. Larva de Tecia solanivora (Lepidoptera: Gelichiidae), B. Adulto de Premnotrypes vorax (Coleoptera: Curculionidae), C. Adultos y pupas de Hypothenemus hampei (Coleoptera: Scolytidae), D. Larvas de Asymmathetes vulcanorum (Coleoptera: Curculionidae). 


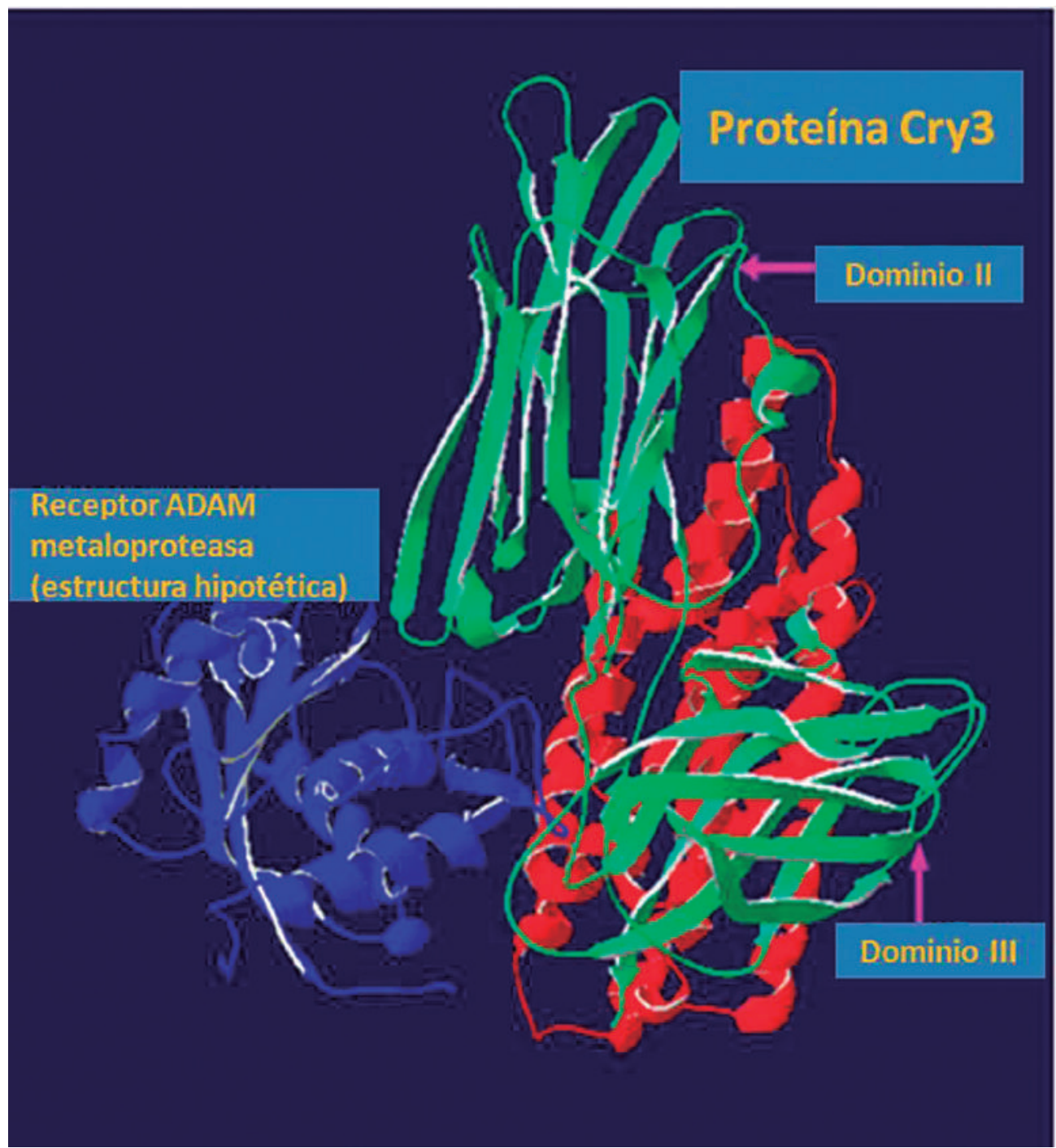

Figura 3. Interacción virtual entre una proteína Cry3 y un posible receptor ADAM metaloproteasa. El receptor ADAM para la toxina Cry3 (34) tiene color azul. El dominio I en la proteína Cry3 es rojo, los dominios II y III (en verde) se indican con flechas. Se puede observar que la interacción se daría en una región que abarca los loops de superficie de los dominios II y III.

\section{Agradecimientos}

Los autores expresan su gratitud a Rojo J. por sus aportes a este manuscrito.

\section{Referencias}

1. Oerke E.-C., Dehne H.-W. Safeguarding production-losses in major crops and the role of crop protection. Crop Protection. 2004; 23: 275-285.

2. Schnepf, E., Crickmore, N., Van Rie, J., Lereclus, D., Baum, J., Feitelson, J., Zeigler, D.R., Dean, D.H. Bacillus thuringiensis and Its Pesticidal Crystal Proteins. Microbiol. Mol. Biol. Rev. 1998; 62: 775-806.

3. Porcar M., Juárez-Pérez V. Aislamiento y establecimiento de una colección de Bacillus thuringiensis. En Bacillus thuringiensis en el control biológico. Bravo, A. y Cerón, J. eds. Universidad Nacional de Colombia. Bogotá, Colombia. 2004; pp. 69-100.
4. Balaraman K. 2005. Occurrence and diversity of mosquitocidal strains of Bacillus thuringiensis. J. Vector Borne Dis. 42:8186.

5. Iriarte J., Bel Y., Ferrandis M. D., Andrew, R., Murillo J. Ferre J. Caballero P. Environmental distribution and diversity of Bacillus thuringiensis in Spain. Syst. Appl. Microbiol. 998; 21: 97-106.

6. Ruiz de Escudero I., Ibañez I., Padilla M., Carnero A., Caballero P. Aislamiento y caracterización de nuevas cepas de Bacillus thuringiensis procedentes de tierras canarias. Bol. San. Veg. Plagas. 2004; 30: 703-712.

7. López-Pazos S.A., Martínez J.W., Castillo A.X., Cerón Salamanca J.A. Presence and significance of Bacillus thuringiensis Cry proteins associated with the Andean weevil Premnotrypes vorax (Coleoptera: Curculionidae). Rev. Biol. Trop. 2009; 57: $1235-1243$. 
8. Bravo A. Sarabia S., López, L., Ontiveros H., Abarca C., Ortiz A., Ortiz M., Lina L., Villalobos F. J., Pena G., Núńez-Valdez M. E., Soberon M., Quintero R. Characterization of $c r y$ genes in a Mexican Bacillus thuringiensis strain collection. Appl. Environ. Microbiol. 1998; 64: 4965-4972.

9. Maduell P., Callejas R., Cabrera K.R., Armengol G.,Orduz S. Distribution and characterization of Bacillus thuringiensis on the phylloplane of species of Piper (Piperaceae) in three altitudinal levels. Microb. Ecol. 2002; 44: 144-153.

10. Vachon V., Laprade R., Schwartz J.L. ańo 2012. Current models of the mode of action of Bacillus thuringiensis insecticidal crystal proteins: A critical review. J. Invertebr. Pathol. In press.

11. 1. van Frankenhuyzen K. 2009. Insecticidal activity of Bacillus thuringiensis crystal proteins. J Invertebr Pathol. 101: 1-16.

12. Galitsky N., Cody V., Wojtczak A., Ghosh D., Luft J.R. Structure of the insecticidal bacterial delta-endotoxin Cry3Bb1 of Bacillus thuringiensis. Acta. Crystallogr. 2001; D 57:11011109.

13. Morse R.J, Yamamoto T., Stroud R.M. Structure of Cry2Aa suggests an unexpected receptor binding epitope. Structure. 2001; 9: 409-417.

14. Pardo-López L., Soberón M., Bravo A. Bacillus thuringiensis insecticidal three-domain Cry toxins: mode of action, insect resistance and consequences for crop protection. FEMS Microbiol. Rev. In press. 2012.

15. de Maagd R.A., Bravo A., Crickmore N. How Bacillus thuringiensis has evolved specific toxins to colonize the insect world. Trends Genet. 2001; 17: 193-199.

16. Sanahuja, G., Banakar, R., Twyman, R. M., Capell, T. and Christou, P. 2011. Bacillus thuringiensis: a century of research, development and commercial applications. Plant Biotechnology Journal, 9: 283 -300.

17. Aronson A.I., Shai Y. Why Bacillus thuringiensis insecticidal toxins are so effective: unique features of their mode of action. FEMS Microbiology Letters. 2001; 195: 1-8.

18. Bravo A., Gill S.S., Soberón M. Mode of action of Bacillus thuringiensis Cry and Cyt toxins and their potential for insect control. Toxicon. 2007; 49: 423-435.

19. Tiewsiri K., Angsuthanasombat C. Structurally conserved aromaticity of Tyr249 and Phe264 in helix 7 is important for toxicity of the Bacillus thuringiensis Cry4Ba toxin. J Biochem Mol Biol. 2007; 40:163-171.

20. Roh J.Y., Choi J.Y., Li M.S., Jin B.R., Je Y.H. Bacillus thuringiensis as a Specific, Safe, and Effective Tool for Insect Pest Control. J. Microbiol. Biotechnol. 2007; 17: 547-559.

21. Pigott C.R., Ellar D.J. Role of Receptors in Bacillus thuringiensis Crystal Toxin Activity. Microbiol. Mol. Biol. Rev. 2007;71: 255-281.
22. 1. Bravo A, Gómez I, Porta H, García-Gómez BI, RodriguezAlmazan C, Pardo L, Soberón M. 2013. Evolution of Bacillus thuringiensis Cry toxins insecticidal activity. Microb Biotechnol. 6: 17-26.

23. Shu C., Zhang J. año 2009. Current patents related to Bacillus thuringiensis insecticidal crystal proteins. Recent. Pat. DNA Gene Seq. 3: 26-28.

24. Rosas-García N.M. Biopesticide production from Bacillus thuringiensis: an environmentally friendly alternative. Recent Pat. Biotechnol. 2009; 3: 28-36.

25. Buitrago G. La producción de ingredientes activos con Bacillus thuringiensis. En Bacillus thuringiensis en el control biológico. Bravo, A. y Cerón, J. eds. Editorial Buena Semilla. Bogotá, Colombia. 2004; pp. 233-273.

26. Içgen Y., Içgen B., Özcengiz, G. año 2002 (a). Regulatión of crystal protein biosynthesis by Bacillus thuringiensis: II. Effects of carbon and nitrogen sources. Rev. Microbiol. 153: 605-609.

27. Sauka D., Benintende G. Bacillus thuringiensis: generalidades un acercamiento a su empleo en el biocontrol de insectos lepidópteros que son plagas agrícolas. Revista Argentina de Microbiología. 2008; 40:124-140.

28. Brookes G., Barfoot P. GM Crops: The First Ten Years-Global Socio-Economic and Environmental Impacts. año 2006; ISAAA Brief No. 36. ISAAA: Ithaca, N..Y.

29. Kumar S, Chandra A., Pandey K.C. Bacillus thuringiensis (Bt) transgenic crop: an environment friendly insect-pest management strategy. J. Environ. Biol. 2008. 29:641-653.

30. Cerón J. Productos comerciales: nativos y recombinantes. En $B a-$ cillus thuringiensis en el control biológico. Bravo, A. y Cerón, J. eds. Editorial Buena Semilla. Bogotá, Colombia. año 2004; pp. 123-147.

31. Mohan Babu R., A. Sajeena, K. Seetharaman, Reddy M.S. año 2003. Advances in genetically engineered (transgenic) plants in pest management-an over view. Crop Protection. 22: 1071-1086.

32. Martínez, W. 2004. Evaluación de la toxicidad de Bacillus thuringiensis. En Bacillus thuringiensis en el control biológico. Bravo, A. y Cerón, J. eds. Universidad Nacional de Colombia. Bogotá, Colombia. pp. 207-232.

Navon, A. 2000. Bioassays of Bacillus thuringiensis products used against agricultural pests. CAB International. Bioassays of entomopathogenic microbes and nematodes (eds. A. Navon and K.R.S. Ascher). pp. 1-24.

Ochoa-Campuzano C, Real MD, Martínez-Ramírez AC, Bravo A, Rausell C. 2007. An ADAM metalloprotease is a Cry3Aa Bacillus thuringiensis toxin receptor. Biochem. Biophys. Res. Commun. 362: 437-442. 